\title{
Subcyclo laser procedure results in patients with glaucoma
}

\author{
Lutic Irina, Dragne Carmen, Filip Mircea, Filip Andrei, Nicolae Miruna, Moisescu Raluca, \\ Ungureanu Ileana, Triantafyllidis Grigorios, Antonescu Cristina \\ AMA Optimex Clinic, Bucharest, Romania
}

Correspondence to: Lutic Irina,

AMA Optimex Clinic, Bucharest, 54 Toamnei Street, Code 020713, Bucharest, Romania,

Mobile phone: +40724 462 379, E-mail: irina.lutic@amaoptimex.ro

Accepted: December 19th, 2018

\begin{abstract}
Purpose. To analyse the results of subCyclo (subliminal transscleral cyclophotocoagulation) laser procedure for patients with glaucoma.

Material and methods. The study included 50 eyes of 32 patients diagnosed with various subtypes of glaucoma for which we performed subliminal transscleral cyclophotocoagulation under retrobulbar anesthesia. After the procedure, all patients were advised to continue their antiglaucoma medication until further notice and we added a topical steroid for 2 weeks. The minimum follow-up period was 6 months.

Results. The mean IOP (intraocular pressure) decreased from the preoperative value of $26.27 \mathrm{mmHg}( \pm 6.52)$ to $15.9 \mathrm{mmHg}( \pm 5.72)$ one day after the treatment. At 7 days, the average IOP was $13.72 \mathrm{mmHg}( \pm 4.31), 15.81 \mathrm{mmHg}( \pm 3.69)$ at 6 weeks, $15.94 \mathrm{mmHg}$ $( \pm 5.66)$ at 3 months and $16.32 \mathrm{mmHg}( \pm 5.24)$ at 6 months. The second intervention was performed in 9 eyes due to poor IOP control after the first procedure, two eyes developed ocular hypertonia 6-8 hours after the procedure and one eye presented mydriasis after the procedure.

Conclusions. Early results for this study showed that subCyclo laser procedure could determine a satisfactory decrease of the IOP with a low risk of complications.

Keywords: subliminal cyclophotocoagulation, glaucoma, intraocular pressure

Abbreviations

$\mathrm{IOP}=$ intraocular pressure, $\mathrm{TSCPC}=$ transscleral cyclophotocoagulation, $\mathrm{POAG}=$ primary open-angle glaucoma, $\mathrm{NVG}=$ neovascular glaucoma, $\mathrm{BCVA}=$ best corrected visual acuity
\end{abstract}

\section{Introduction}

Transscleral cyclophotocoagulation uses a continuous diode laser and it has been a treatment option in advanced glaucoma cases with suboptimal IOP control, for a long time. The main effect is the destruction of the ciliary body by acting on the following structures: ciliary epithelium and stroma. The main target of the laser is the melanin located in the pigmented ciliary body epithelium. The result of this treatment is diminished aqueous secretion. Because of its high rate of complications, TSCPC has been a last option in eyes with preserved function and uncontrolled, severe glaucoma when other treatment options are exhausted [1].

SubCyclo has the same principle of action as TSCPC but avoids the side effects of the previous mentioned procedure. It is a nondestructive laser treatment for all types of glaucoma, advanced or moderate stage, 
unresponsive to other therapeutic alternatives or in cases with high risk of surgery [2].

For this procedure, an infrared diode laser is used with $810 \mathrm{~nm}$ wavelength to stimulate the ciliary body structures and the uveoscleral pathway. This way it reduces the production of the aqueous humour and facilitates the uveoscleral outflow, with IOP reduction as a final effect.

The continuous-wave beam is segmented so that the whole energy is transmitted through ultrashort and repetitive pulses (they represent "time on"- when the laser is active) separated by rest periods ("time off"), which allow tissue cooling with minimal adjacent tissue damage. The main goal of our research was to analyse the profile of this procedure in terms of safety and efficacy of IOP reduction in glaucoma patients.

\section{Material and methods}

In this research we included patients with various subtypes of glaucoma who underwent subliminal transscleral cyclophotocoagulation if they had worsening IOP control and/ or worsening visual fields, if they did not wish/ or were not good candidates for invasive surgeries.

The preoperative assessment included a complete ophthalmic evaluation.

The anesthesia consisted in a retrobulbar block of ropivacaine and 4\% lidocaine delivered before the procedure.

The tip of the probe was moved in a "painting" motion along the upper and lower hemisphere, $3 \mathrm{~mm}$ behind the limbus, sparing the 3 and 9 o'clock positions. The total time of the treatment was 160 seconds, corresponding to 80 seconds for each hemisphere.

We followed the recommendations of the producer and we adjusted the treatment settings as mentioned in Table 1.

\section{Power level 2000mW}

Duty Cycle 25\%

(time on $0,62 \mathrm{sec}$, time off $1.9 \mathrm{sec}$ )

(time on $0.5 \mathrm{sec}$, time off $1.1 \mathrm{sec}$ )

- No previous history of severe ocular inflammation

- No active inflammation (conjunctival or uveal)

- No severe keratitis or corneal ulcer

Patients received a post-operative dose of prednisolone acetate ophthalmic suspension and a dose of levofloxacin hemihydrate and the eye was patched for 8 hours. All of them were started on topical steroid that was tapered progressively by the end of the second week after the laser and they were advised to continue the IOP-lowering treatment until further notice. Patients were seen postoperatively on day 1 , day 7 , week 6 , months 3 and 6 . At each check-up, we performed

Table 2. Types of glaucoma

$\begin{array}{ll}\text { POAG } & 40 \text { eyes } \\ \text { NVG } & 3 \text { eyes } \\ \text { Uveitic glaucoma } & 2 \text { eyes } \\ \text { Juvenile glaucoma } & 2 \text { eyes } \\ \text { Pigmentary glaucoma } & 2 \text { eyes } \\ \text { Posttraumatic glaucoma } & 1 \text { eye }\end{array}$

- Active inflammation (conjunctival or uveal)

- Preserved good BCVA or moderated visual field defects

a slit-lamp examination, Goldmann tonometry and registered BCVA.

\section{Results}

Fifty eyes of thirty-two patients with different types of glaucoma (summarized in Table 2) were accepted in this survey. There were 12 women and 20 men and the mean age was 54,7 years. 
Baseline IOP was $26.27 \mathrm{mmHg}( \pm 6.52)$ and the average number of medications was 3.14. Mean IOP decreased to $15.9 \mathrm{mmHg}( \pm 5.72)$ one day after the procedure. At one week, mean IOP was $13.72 \mathrm{mmHg}( \pm 4.31), 15.81 \mathrm{mmHg}( \pm 3.69)$ at 6 weeks, $15.94 \mathrm{mmHg}( \pm 5.66)$ at 3 months. Six months after the laser, average IOP was 16.32 $\mathrm{mmHg}( \pm 5.24)$ and the number of medications was 2,56 .

For this period of follow-up, we registered a mean IOP reduction of $37 \%$ from baseline and $18.47 \%$ average reduction of medications (Fig. 1).

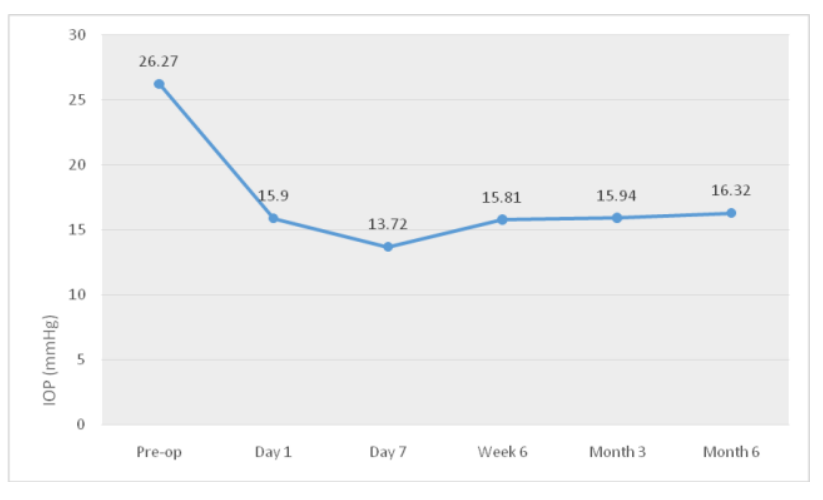

Fig. 1 IOP evolution after subCyclo

Two eyes developed ocular hypertonia 6-8 hours after the procedure, controlled with pressure-lowering medications, one eye presented mydriasis after the procedure, which responded to topical administration of Pilocarpine $1 \%$ for one week. Nine eyes required a second intervention due to inadequate IOP control after the first laser treatment (Table 3).

Table 3. Number of eyes requiring a second laser treatment

$\begin{array}{ll}\text { POAG } & 4 \text { eyes } \\ \text { NVG } & 2 \text { eyes } \\ \text { Uveitic glaucoma } & 1 \text { eye } \\ \text { Juvenile glaucoma } & 1 \text { eye } \\ \text { Pigmentary glaucoma } & 1 \text { eye }\end{array}$

No patient developed hypotony, all patients were pain free during and after the procedure and BCVA remained stable by the end of the follow-up.

\section{Discussions}

Current glaucoma therapies include topical medications, laser therapies, microinvasive glaucoma surgery, and incisional glaucoma surgery. Subliminal transscleral cyclophotocoagulation does not induce fatal architectural damage to the cellular structure and proves to be an effective option to fill the gaps between topical medical therapy, MIGS, and traditional glaucoma-filtering surgery [3].

Evidence collected in the past years has proved that subliminal transscleral cyclophotocoagulation can provide a satisfactory decrease of IOP in patients with moderate to advanced glaucoma [4-6]. We must take into consideration the major advantages of this procedure: it has a reduced rate of complications and we can repeat it in order to improve the IOP control.

We must be aware that the location of the ciliary body varies between patients and even among quadrants of the same eye and adding transscleral illumination of the ciliary body can increase the accuracy of the probe localization.

In our opinion, we need more studies to optimize the profile of this treatment. In order to improve IOP control, we consider that the treatment settings must be adjusted to the type and the stage of glaucoma and to the type of the procedure (first intervention vs. reintervention).

Subliminal transscleral cyclophotocoagulation has a good profile in terms of safety and efficacy and this makes it a good option treatment for all cases of uncontrolled glaucoma, either as a single procedure or combined with glaucoma surgery [7].

\section{References}

1. Roberto GC. Cyclophotocoagulation. In: Ophthalmic Surgery: Principles and practice e-book. In: Spaeth GL, Danesh-Meyer H, Goldberg I, Kampik A, editors. 2012, Elsevier Health Sciences, 318-325.

2. Ndulue JK, Rahmatnejad K, Sanvicente C, Wizov SS, Moster MR. Evolution of cyclophotocoagulation. J. Ophthalmic Vis Res. 2018 Jan-Mar; 13(1):55-61. doi:10.413/jovr.jovr_190_17.

3. Toyos MM, Toyos R. Clinical Outcomes of Micropulsed Transcleral Cyclophotocoagulation in Moderate to Severe Glaucoma. J Clin Exp Ophthalmol. 2016; 7:6. doi: 10.4172/2155-9570.1000620. 
4. Tan AM, Chockalingam M, Aquino MC, Lim ZI, See JL, Chew PT. Micropulse transscleral diode laser cyclophotocoagulation in the treatment of refractory glaucoma. Clin Exp Ophthalmol. 2010; 38:266-72.

5. Aquino MC, Barton K, Tan AM, Sng C, Li X, Loon SC et al. Micropulse versus continuous wave transscleral diode cyclophotocoagulation in refractory glaucoma: A randomized exploratory study. Clin Exp Ophthalmol. 2015; 43:40-6.

6. Barac R, Vuzitas M, Balta F. Choroidal thickness increase after micropulse transscleral cyclophotocoagulation. Rom J Ophthalmol. 2018 Apr-Jun; 62(2):144-148.

7. Emanuel ME, Grover DS, Fellman RL, Godfrey DG, Smith O, Butler MR, Kornmann HL, Feuer WJ, Goyal S. Micropulse Cyclophotocoagulation: Initial Results in Refractory Glaucoma. J Glaucoma. 2017 Aug; 26(8):726729. doi: 10.1097/IJG.0000000000000715. 